\title{
Low Power Dissipation Filter of Single-phase DC-AC Inverter for Photovoltaic Based Homescale Electric Power System
}

\author{
Ikhsan Hidayat ${ }^{1}$, Faizal Arya Samman ${ }^{2}$, Rhiza S. Sadjad ${ }^{3}$ \\ ${ }^{123}$ Department of Electrical Engineering, Universitas Hasanuddin Makassar, \\ Indonesia, 92119 \\ \{1ikhsan_hidayat@ung.ac.id, ${ }^{2}$ faizalas@unhas.ac.id, ${ }^{3}$ rhiza@unhas.ac.id\}
}

\begin{abstract}
This paper presents a number of experiments through simulations to find out the type of inverter that is suitable for homescale needs. By simulating 2 different inverter topologies, multilevel inverters and single-phase inverters. Testing is done using three different switching control techniques, namely by using PWM (Pulse Width Modulation), SPWM (Sinusoidal Pulse-Width Modulation) and PWL (Piecewise - Linear). Each topology will also be tested using transformers and without transformers. The simulation results on PSpice display using a DC voltage source of 48 Volt or 220 Volt and produce AC output of 220-227 Volts, which has a THD (Total Harmonic Distortion) of $1.81 \%$ and efficiency of $98 \%$.
\end{abstract}

Keywords : Power Electronics, Multilevel Inverter, Single-Phase Inverter, $P W M$, SPWM.

\section{Introduction}

Currently there are many research papers with power electronic themes about inverters and multilevel inverters, but each still has weaknesses, such as a single phase inverter that only uses a number of switching components but still requires filters to get good sinusoidal signals, while multilevel Inverters are the most efficient type of inverter because they solve the weaknesses faced by conventional inverter [1]. Multilevel inverter is a type of electronic power converter that can provide or produce the desired $\mathrm{AC}$ voltage level at the output of the converter using several numbers of low level DC voltage as input with / without using any filter circuit, but multilevel inverter requires more switching components than single-phase inverter.The multilevel that will be used is to use 3 separate DC sources. Multilevel inverter equipment is arranged cascade using a separate DC source, so as to produce three AC output voltage wave levels. This means that the number of inverters arranged in the cascade is three where the output is arranged in series. Multilevel Inverter 1 Phase configuration can be seen in the following figure 1 .

In Mixed-Level Hybrid Multilevel Cells multilevel inverter [2] the voltage levels of the cascade inverter cells are the same. However, it is possible to have different voltage levels between cells and can be referred to as asymmetric hybrid multilevel inverter. Figure 1 shows an example of 3 separate dc-bus levels, one with v2/3 and vdc 2 and vdc 3 is $\mathrm{Vdc} 1 / 6$. Depending on the availability of the dc source, the voltage level is not limited to a certain ratio. 


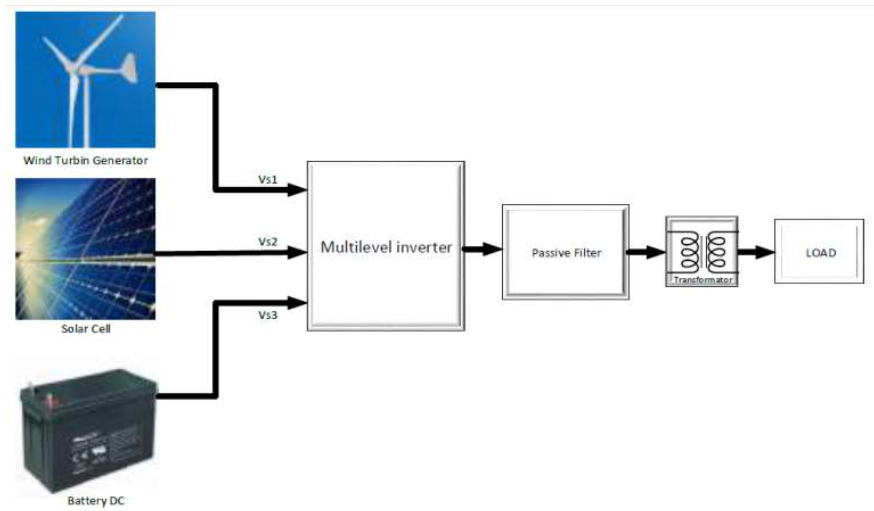

Fig. 1. Diagram of a solar-based power generation system of multilevel inverter

Multilevel inverter output voltage can be guided using PWL (Piecewise - Linear) switching control method, while for single-phase inverter output voltage uses PWM (Pulse Width Modulation) switching control method and SPWM (Sinusoidal Pulse-Width Modulation) switching control method, however the problem of the three controls above is total harmonics distortion (THD). To overcome this problem, passive power filters (PPF) are used [6]. To be able to supply electricity to the load, a solar power-based power generation system, single-phase inverter, is shown in Fig.2.

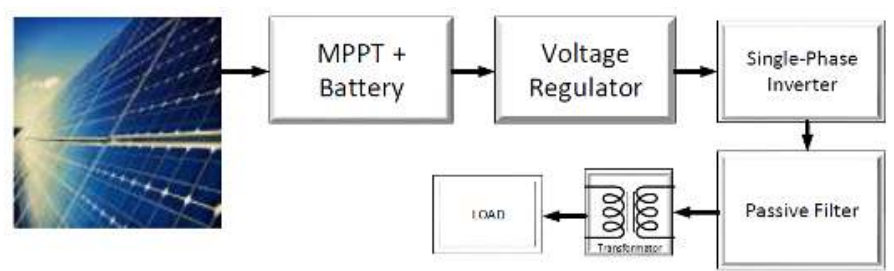

Fig 2. Diagram of a solar-based power generation system of single-phase inverter

The remaining sections in this paper are organized as follows. Section II discusses the design of system models. Section III shows the simulation results. Section IV presents the comparative study presented in quantitative values in some tables. Finally, the work is concluded in Section V.

\section{Material and Methods}

Multilevel Inverters, inverters, filters and transformers are designed, modeled and simulated using the SPICE Program [3]. Signal generators and analysis components are also modeled in the SPICE program. In this design, we will present eight simulation methods that show frequency response, THD, output power, voltage amplitude, and power efficiency as the basis for filter analysis, each using a transformer and without a transformer. Without a transformer here, analogous to the source voltage of 220 Volt, namely with several batteries arranged in series. In addition, the single-phase inverter is divided into 2 parts of the switching control method, namely PWM and SPWM. Whereas for multilevel inverter the swicthing control method used is PWL. For multilevel inverters used multilevel 3 level inverter and multilevel 2 level inverter.

\section{A. Multilevel Inverter Model (Cascaded Multicell Inverter 3 level)}

The topology used in multilevel here is based on the series connection of single-phase inverters with separate dc sources [4]. Fig. 3 shows the power circuit for one phase leg of a six- 
level inverter with three cells in each phase. The resulting phase voltage is synthesized by the addition of the voltages generated by the different cells. Each single-phase full-bridge inverter generates three voltages at the output $+\mathrm{Vdc}, 0$, and $-\mathrm{Vdc}$. This is made possible by connecting the capacitors sequentially to the AC side via the four power switches. The resulting output AC voltage swings from 3 to 3 with six levels, and the staircase waveform is nearly sinusoidal, even without filtering. Figure 3 shows an example of 3 separate dc-bus levels, one with $68 \%$ of Vdc , $\mathrm{vdc} 2$ and vdc 3 is Vdc $16 \%$ of Vdc. Depending on the availability of the dc source, the voltage level is not limited to a certain ratio.

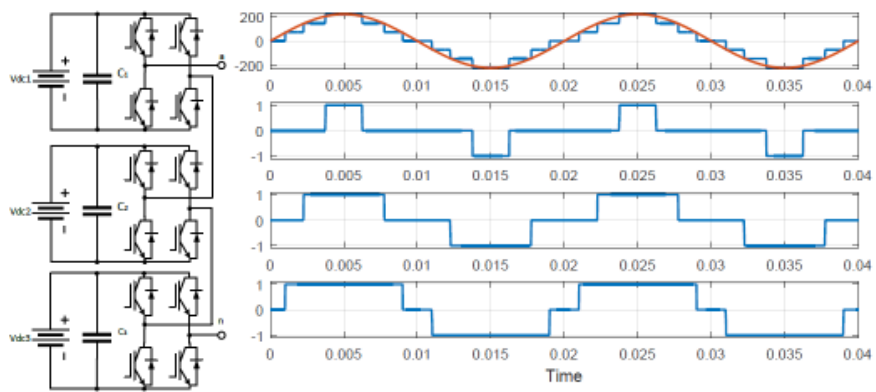

Cascaded inverter circuit topology 3 level and its associated waveform.

For each topology we use 2 tests, namely by using a transformer and without a transformer. For a 48 volt source voltage transformer will be used to reach a voltage of 220 Volt, but for multilevel 3 level testing without using a voltage source transformer of 220Volt, it is assumed that some batteries are arranged in series to get a $220 \mathrm{~V}$ source voltage. The 3 level cascaded inverter circuit topology requires 12 switching MOSFET devices, as well as as many diodes as that.

\section{B. Multilevel Inverter Model (Cascaded Multicell Inverter 2 level).}

After using a multilevel 3 level model, we will try to use a 2 level multilevel inverter to compare which one will get the smallest THD simulation results. For multilevel inverter 2 the level of the number of MOSFETs used is less than the previous multilevel inverter, this is due to the number of levels generated by the multilevel inverter output. The asymectric hybrid cascadeinverter cell topology shows that the more mosfets used, the more levels will be generated, because the output of the mosfet is arranged in series.Cascaded inverter 2 level circuit topology requires 8 switching devices for MOSFETs, as well as many diodes. Fig. 4 shows the power circuit for one phase leg of a four-level inverter with two cells in each phase. That figure shows two separate dc-bus levels, one with $75 \%$ of $\mathrm{Vdc}$, and the other with $25 \%$ of $\mathrm{Vdc}$. Depending on the availability of dc sources, the voltage levels are not limited to a specific ratio. This feature allows more levels to be created in the output voltage, and thus reduces the harmonic contents with less cascaded cells required. 


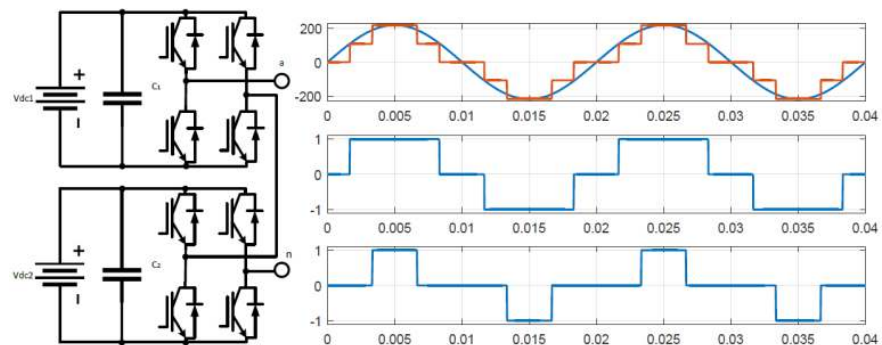

Fig 4. Cascaded inverter circuit topology 2 level and its associated waveform.

\section{Single-Phase Inverter with Transformer Model.}

For the single-phase inverter with transformer the power supply used is a 48 Volt battery, then the transformer is modeled using the PSpice application with $40 \mathrm{mH}$ primary windings and $800 \mathrm{mH}$ secondary windings and magnetic coupling is 1 , which will increase the voltage up to 220 Volt -227 Volt. The circuit scheme with full bridge configuration from a single-phase inverter with transformer is shown in Fig. 5.

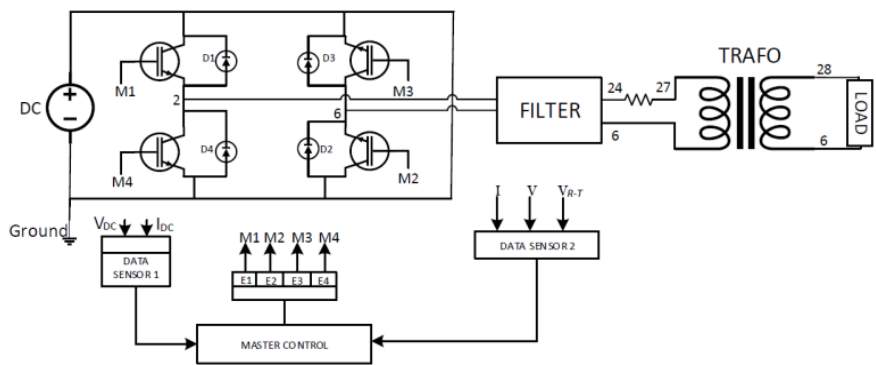

Fig 5. Single-Phase Inverter with Transformer Model.

M1, M2, M3, and M4 as respective switching devices MOSFET. Diodes D1, D2, D3, and D4 are protection elements for the MOSFET, respectively. The single-phase inverter generates filtered output voltages at point 24 and 6 . The output transformer at the point 28 dan 6 . The PPF (Power Passive Filter) output current are I 24,6 . E1, E2, E3 and E4 are power-driven PWM and SPWM switching control signals. Modulated signals are applied to the gate terminals of the MOSFET with a certain period to maintain the desired frequency of $50 \mathrm{~Hz}$ [5].

\section{Single-Phase Inverter without Transformer Model}

For Single-Phase Inverter without transformer the direct source voltage is $220 \mathrm{~V}$, which is assumed by several batteries to be arranged in series. The circuit scheme with full bridge configuration from a single-phase inverter without transformer is shown in Fig. 6. 


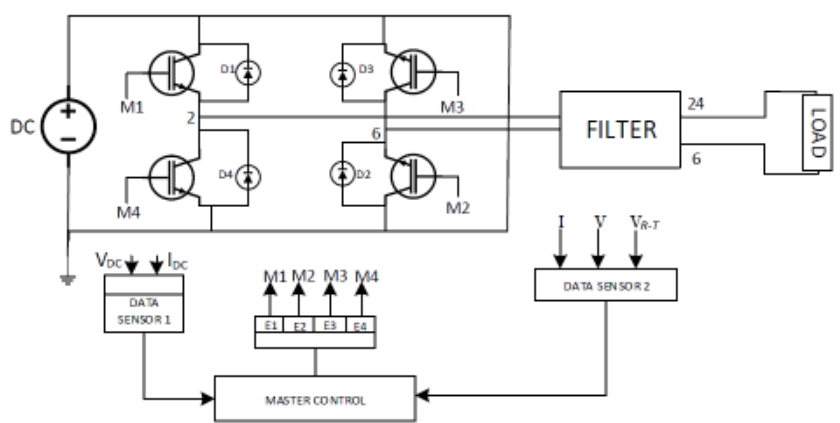

Fig 6. Single-Phase Inverter without Transformer Model (Trafoless).

Just like the previous single-phase inverter model, it is only different from the output of the filter output which no longer uses transformers. This method uses more batteries because the batteries are arranged in series quite a lot. while the battery is expensive.

\section{E. Selected Filter Topology.}

There are several filter models used in various applications with different harmonic traps, size, design cost and characteristics. The choice of passive filter topology used for filter resonance conditions is based on a separate passive shunt filter dampers for many security systems are applied [5]. In this paper, we will analyze the PPF outputs when its output terminal is connected to any type of filters. Fig. 7 shows the selected filter topology, which are briefly explained as follows.

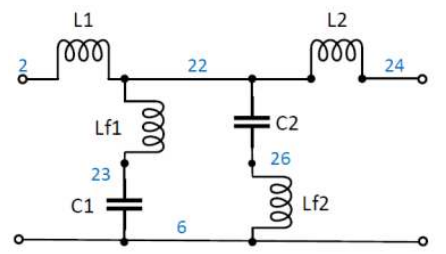

(a) LCL 2-Leg's

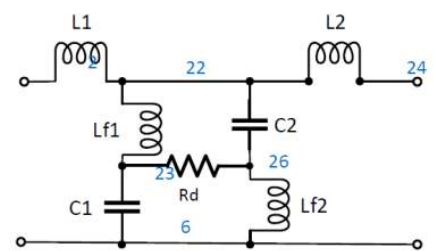

(b) LCL H-Leg's bridge

Fig 7. Type of Filter scematics (a)LCL 2-Legs (b) LCL HLegs bridges.

a) LCL filter with $2 \mathrm{LC}$ legs or multi-tuned trap filter [6]. The filter serves to reduce current loss. Therefore, two equal combinations (LC-LC legs) without resistors is presented. Although this filter has no impedance resistors, it can produce good performance on harmonic reduction. But it has a frequency-loss which is difficult to mediate. It also has a high resonance, but when resonance is encumbered it can be overcome. Point 2 and 6 it's from the output of inverter single-phase, whereas for transformer or load its point 24 and 6.

b) LCL Filter + H-bridge damper. As the completion of the 2-leg's LCL filter, a resistor is inserted to make a bridge between two LC legs. The application of this filter is very suitable for three-phase inverters [7]. For more results on this topic, we refer readers to $[6,7]$ and the references therein. We will try to use this filter on single-phase inverters without transformers. Point 2 and 6 it's from the output of inverter single-phase, while points 24 and 6 are outputs of filters and are also inputs from transformers or loads. The LCL 2-leg's filter is used for single-phase inverters (PWM) and multilevel inverter 
(PWL), while the LCL H-leg's bridge filter is used for single-phase inverters SPWM controlled signal with Transformer.

\section{Results and Discussion}

This section presents several simulation results, i.e power from the input side, inverter output side, power from the load side, efficiency and THD. Each simulation has different parameters, so in this case we will display one by one the parameters used.

\section{A. Selected Switching Control Signal for Analysis.}

The parameters used in the simulation of filters and transformer are shown in Tables. The first simulation results presented in this section are the effectiveness of inverters and multilevel inverters using PWL, PWM and SPWM switching control signals.

\section{B. Parameter of the simulation.}

Three switching control signals, i.e. PWL, PWM or SPWM can be applied. This section analyzes the THD and output voltage amplitude when using one of third switching signals. Fig. 8 shows the time domain output voltage simulation results using third switching signals.

Table I. Parameters Simulation Of 3 Level Cascaded Multilevel Inverter

\begin{tabular}{|c|c|c|c|}
\hline Trafoless/Trafo & \multicolumn{2}{|c|}{ Trafo } & Trafoless \\
\hline input Voltage & \multicolumn{2}{|c|}{$48 \mathrm{~V}$} & $220 \mathrm{~V}$ \\
\hline Output Voltage & \multicolumn{2}{|c|}{$61 \mathrm{~V}$} & $214 \mathrm{~V}$ \\
\hline Frequency & \multicolumn{2}{|c|}{$50 \mathrm{~Hz}$} & $50 \mathrm{~Hz}$ \\
\hline Output Power & \multicolumn{2}{|c|}{$27 \mathrm{Watt}$} & $229 \mathrm{Watt}$ \\
\hline Var./Parameter & LCL 2Leg's & Trafo & LCL 2Leg \\
\hline L1 & $8 \mathrm{mH}$ & - & $8 \mathrm{mH}$ \\
\hline L2 & $55 \mathrm{mH}$ & - & $55 \mathrm{mH}$ \\
\hline Lf1 & $2.3 \mathrm{mH}$ & - & $2.3 \mathrm{mH}$ \\
\hline Lf2 & $1 \mathrm{mH}$ & - & $1 \mathrm{mH}$ \\
\hline C1 & $192 \mathrm{uF}$ & - & $192 \mathrm{uF}$ \\
\hline C2 & $192 \mathrm{uF}$ & - & $192 \mathrm{uF}$ \\
\hline RT & - & $10 \mathrm{Ohm}$ & - \\
\hline L3 & - & $45 \mathrm{mH}$ & - \\
\hline L4 & - & $900 \mathrm{mH}$ & - \\
\hline
\end{tabular}

Table II. Parameters Simulation Of 2 Level Cascaded Multilevel Inverter

\begin{tabular}{|c|c|c|c|}
\hline Trafoless/Trafo & \multicolumn{2}{|c|}{ Trafo } & Trafoless \\
\hline input Voltage & \multicolumn{2}{|c|}{$48 \mathrm{~V}$} & $220 \mathrm{~V}$ \\
\hline Output Voltage & \multicolumn{2}{|c|}{$83 \mathrm{~V}$} & $227 \mathrm{~V}$ \\
\hline sFrequency & \multicolumn{2}{|c|}{$50 \mathrm{~Hz}$} & $50 \mathrm{~Hz}$ \\
\hline Output Power & \multicolumn{2}{|c|}{$34 \mathrm{Watt}$} & $275 \mathrm{Watt}$ \\
\hline Var./Parameter & LCL 2Leg's & Trafo & LCL 2Leg \\
\hline L1 & $14 \mathrm{mH}$ & - & $14 \mathrm{mH}$ \\
\hline L2 & $50 \mathrm{mH}$ & - & $50 \mathrm{mH}$ \\
\hline Lf1 & $3 \mathrm{mH}$ & - & $3 \mathrm{mH}$ \\
\hline Lf2 & $1.7 \mathrm{mH}$ & - & $1.7 \mathrm{mH}$ \\
\hline
\end{tabular}




\begin{tabular}{|c|c|c|c|} 
C1 1 & $142 \mathrm{uF}$ & - & $142 \mathrm{uF}$ \\
\hline C2 & $180 \mathrm{uF}$ & - & $180 \mathrm{uF}$ \\
\hline RT & - & $10 \mathrm{Ohm}$ & - \\
\hline L3 & - & $45 \mathrm{mH}$ & - \\
\hline L4 & - & $900 \mathrm{mH}$ & - \\
\hline
\end{tabular}

Tabel III. Parameters Simulation Of Single-Phase Inverter ( SPWM )

\begin{tabular}{|c|c|c|c|}
\hline Trafoless/Trafo & \multicolumn{2}{|c|}{ Trafo } & Trafoless \\
\hline input Voltage & \multicolumn{2}{|c|}{$48 \mathrm{~V}$} & $220 \mathrm{~V}$ \\
\hline Output Voltage & \multicolumn{2}{|c|}{$190 \mathrm{~V}$} & $249 \mathrm{~V}$ \\
\hline Frequency & \multicolumn{2}{|c|}{$50 \mathrm{~Hz}$} & $50 \mathrm{~Hz}$ \\
\hline Output Power & \multicolumn{2}{|c|}{$81 \mathrm{Watt}$} & $150 \mathrm{Watt}$ \\
\hline Var./Parameter & LCL 2Leg's & Trafo & LCL H Leg \\
\hline L1 & $10 \mathrm{mH}$ & - & $14 \mathrm{mH}$ \\
\hline L2 & $15 \mathrm{mH}$ & - & $50 \mathrm{mH}$ \\
\hline Lf1 & $1.5 \mathrm{mH}$ & - & $3 \mathrm{mH}$ \\
\hline Lf2 & $4.5 \mathrm{mH}$ & - & $1.7 \mathrm{mH}$ \\
\hline C1 & $256 \mathrm{uF}$ & - & $142 \mathrm{uF}$ \\
\hline C2 & $260 \mathrm{uF}$ & - & $180 \mathrm{uF}$ \\
\hline R & - & - & $38 \mathrm{Ohm}$ \\
\hline RT & - & $10 \mathrm{Ohm}$ & - \\
\hline L3 & - & $45 \mathrm{mH}$ & - \\
\hline L4 & - & $900 \mathrm{mH}$ & - \\
\hline \multicolumn{3}{|c}{} \\
\hline
\end{tabular}

\section{Measurement and Comparative Statistics}

This section presents the quantitative data of the simulation results presented in the previous section. The voltage provided varies with each inverter, ranging from $61 \mathrm{~V}$ to $339 \mathrm{~V}$. Table 3 presents quantitative simulation data from all inverters. It seems that 3 levels of multilevel inverter (transformer) provide weakening performance for the best THD for output voltage and also have the highest output power of 229 Watt. But for the efficiency of the power produced only $0.7 \%$. Single-phase inverter with PWM has higher power efficiency than others, and also has a fairly high output voltage of $227 \mathrm{~V}$.

Table IV. Parameters Simulation Of 2 Single - Phase Inverter ( PWM )

\begin{tabular}{|c|c|c|c|}
\hline Trafoless/Trafo & \multicolumn{2}{|c|}{ Trafo } & Trafoless \\
\hline input Voltage & \multicolumn{2}{|c|}{$48 \mathrm{~V}$} & $220 \mathrm{~V}$ \\
\hline Output Voltage & \multicolumn{2}{|c|}{$227 \mathrm{~V}$} & $229 \mathrm{~V}$ \\
\hline Frequency & \multicolumn{2}{|c|}{$50 \mathrm{~Hz}$} & $50 \mathrm{~Hz}$ \\
\hline Output Power & \multicolumn{2}{|c|}{$116 \mathrm{Watt}$} & $225 \mathrm{Watt}$ \\
\hline Var./Parameter & LCL 2Leg's & Trafo & LCL 2Leg \\
\hline L1 & $10 \mathrm{mH}$ & - & $14 \mathrm{mH}$ \\
\hline L2 & $15 \mathrm{mH}$ & - & $50 \mathrm{mH}$ \\
\hline Lf1 & $5 \mathrm{mH}$ & - & $3 \mathrm{mH}$ \\
\hline Lf2 & $5 \mathrm{mH}$ & - & $1.7 \mathrm{mH}$ \\
\hline C1 & $195 \mathrm{uF}$ & - & $142 \mathrm{uF}$ \\
\hline
\end{tabular}




\begin{tabular}{|c|c|c|c|} 
C2 & $195 \mathrm{uF}$ & - & $180 \mathrm{uF}$ \\
\hline RT & - & $10 \mathrm{Ohm}$ & - \\
\hline L3 & - & $40 \mathrm{mH}$ & - \\
\hline L4 & - & 800 & - \\
\hline
\end{tabular}
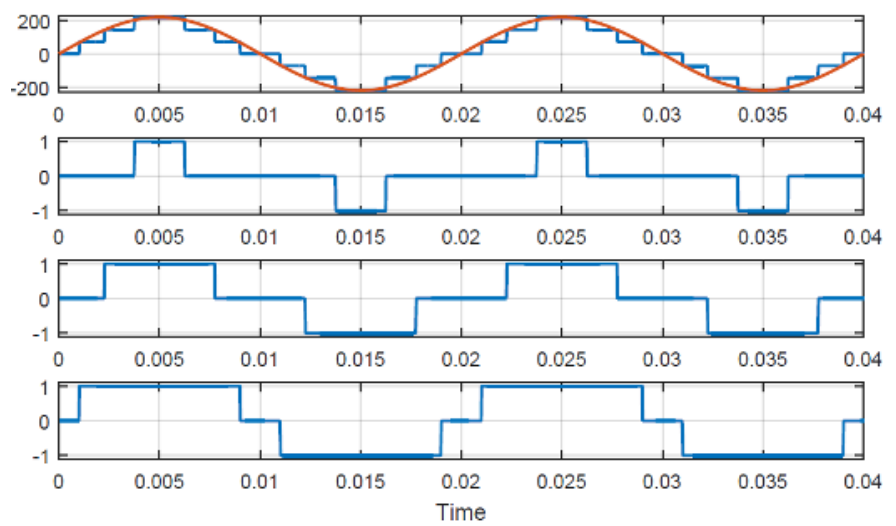

(a) PWL switching control method of 3 level cascaded multilevel inverter.
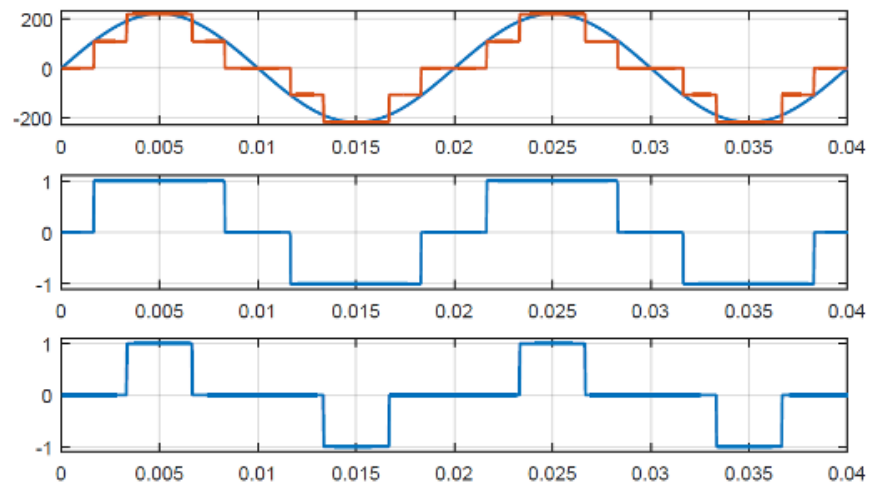

(b) PWL switching control method of 2 level cascaded multilevel inverter. 

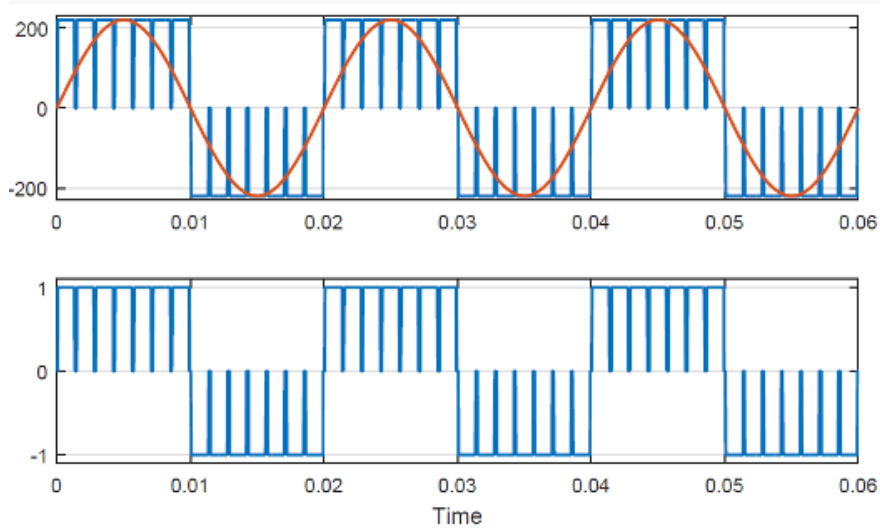

(c) SPWM switching control method of single-phase inverter.
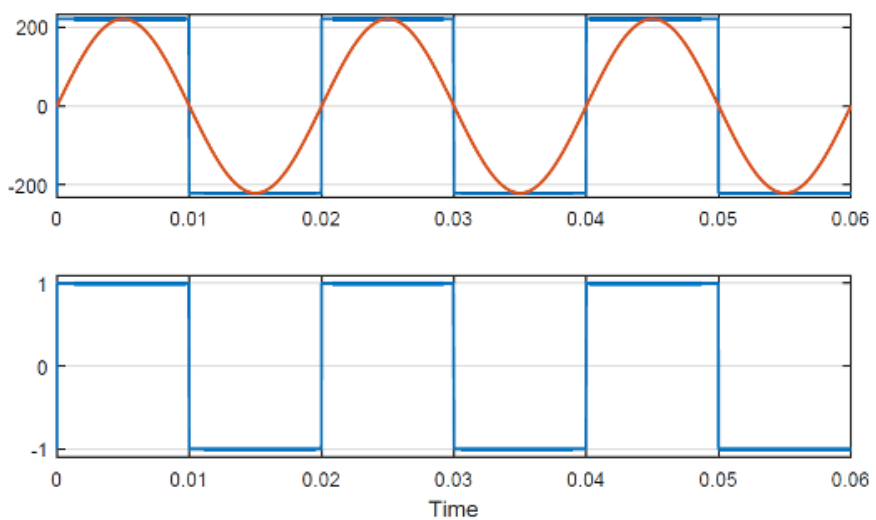

(d) PWM switching control method of single-phase inverter.

Fig 8. Transient simulation of the PWL,SPWM and PWM switching control methods.

Table V. The Simulation Result Data

\begin{tabular}{|l|c|c|c|l|c|}
\hline Inverter & T/TL & THD & Voltage & $\begin{array}{c}\text { Power } \\
\text { (Watt) }\end{array}$ & $\begin{array}{c}\text { Effici. } \\
\text { (P) }\end{array}$ \\
\hline \multirow{2}{*}{ 3ML } & $\mathrm{T}$ & $3.88 \%$ & $61 \mathrm{~V}$ & $18 \mathrm{~W}$ & $18 \%$ \\
\cline { 2 - 6 } & $\mathrm{TL}$ & $1.31 \%$ & $214 \mathrm{~V}$ & $229 \mathrm{~W}$ & $0.7 \%$ \\
\hline \multirow{2}{*}{$\mathbf{2 M L}$} & $\mathrm{T}$ & $2.39 \%$ & $83 \mathrm{~V}$ & $34 \mathrm{~W}$ & $83 \%$ \\
\cline { 2 - 6 } & $\mathrm{TL}$ & $2.73 \%$ & $227 \mathrm{~V}$ & $275 \mathrm{~W}$ & $48 \%$ \\
\hline \multirow{2}{*}{ SPSPWM } & $\mathrm{T}$ & $1.84 \%$ & $190 \mathrm{~V}$ & $81 \mathrm{~W}$ & $35 \%$ \\
\hline \multirow{2}{*}{ SPPWM } & $\mathrm{TL}$ & $3.19 \%$ & $219 \mathrm{~V}$ & $150 \mathrm{~W}$ & $3 \%$ \\
\hline & $\mathrm{T}$ & $1.81 \%$ & $227 \mathrm{~V}$ & $116 \mathrm{~W}$ & $98 \%$ \\
\hline
\end{tabular}

The explanation for abbreviations in table $\mathrm{V}$ is as follows: $3 \mathrm{ML}$ is 3 level multilevel inverter, $2 \mathrm{ML}$ is 2 level multilevel inverter, SPSPWM is single-phase inverter with SPWM control 
method, SPPWM is single-phase inverter with PWM control method, T / TL is Transformer or Transformer less.

\section{Conclusion}

Based on the results of the simulations we have done, it can be concluded that: 1 . to get a low power dissipation using a simple square wave (PWM) that is simple and maximized on the use of a suitable filter, besides that the selection of filters can significantly reduce the THD. no need to use SPWM or PWL. 2. In the results of this simulation it was found that the LCL Filter + Hbridge damper cannot achieve power dissipation as in the previous study [8], so it can be seen that the filter is only suitable for 3 phase inverters and is not compatible with single-phase inverters and multilevel inverter. 3. use of LCL filter with 2 LC legs are very suitable for use in single-phase inverters (transformers) with the PWM swichting control method. this is evidenced by the results of the simulation of power dissipation obtained which is the greatest among the others, which is equal to $98 \%$ and the resulting THD is $1.81 \%$, this is under the IEEE standard [9].With an input voltage of $48 \mathrm{~V}$ it produces an output voltage of $227 \mathrm{~V}$. 4. Besides the use of a transformer on a single-phase inverter with a PWM swichting control method can increase the power (watts) of the inverter, this is evidenced by the output power of an inverter which is only $92 \mathrm{~W}$ up to $116 \mathrm{~W}$. 5. In terms of the number of components it is very clear that single-phase inverters only require fewer components compared to multilevel inverters.

\section{Acknowledgements}

The authors gratefully acknowledge the Ministry of Research, Technology and Higher Education of the Republic of Indonesia (by Direktorat Riset \& Pengabdian Masyarakat-DRPM) for funding our research in 2019.

\section{References}

[1] K. Sato, H. Haga and S.K Nagaoka, Single-Phase 7-Level Inverter For Reducing Number Of Switches, Intelec, Int. Telecommun Energy Conf., Vol 2016-September, 2016.

[2] J. Rodriguez, J Lai and F Zeng, Multilevel Inverters: A Survey of Topologies, Controls, and Applications, IEEE Transactions on Industrial Electronics, vol 49, Pages 724-738., August-2002.

[3] V Letsoin, F A Samman, A E U Salam, Three-Phase DC-AC Inverter with Low Power Dissipation Filter For Photovoltaic-Based Micro-Grid Scale Electric Power System, The 9th International Conference on Electrical, Electronics, Communications, Controls and Informatics System, Batu City, Indonesia,,October,2018.

[4] Tuinenga Paul W. Spice A Giude to Circuit and Analysis Using PSpice., New Jersey: Prentice Hall.

[5] Cadence PSpice Reference Guide. , Cadence Design Systems. 2000.

[6] F. A. Samman and A. Azhari,Dc/ac power converter for home scale electricity systems powered by renewable energy, in Proc. of the 2016 Intl Conf. on Smart Green Technology in Electrical and Information Systems (ICSGTEIS), 2016, pp. 149154.

[7] N.-C. Yang and M.-D. Le, Optimal design of passive power filters based on multiobjective bat algorithm and pareto front, Applied Soft Computing, vol. 35, pp. 257266, 2015.

[8] M. Buyuk, A. Tan, M. Tumay, and K. C. Bayindir, Topologies, generalized designs, passive and active damping methods of switching ripple filters for voltage source inverter: $A$ 
comprehensive review, Renewable and Sustainable Energy Reviews, vol. 62, pp. 46 69, 2016.

[9] IEEE, IEEE Standard for Metal-Oxide Surge Arresters for AC Power Circuits (above 1 $\mathrm{kV}$ ). IEEE SA Standards Board, Surge Protective Devices Committee of the IEEE Power Engineering Society, 1999. 